\title{
Histopathological and histochemical investigation of diclofenac induced visceral gout in domestic fowl
}

\author{
R. S. Arya ${ }^{1 *}$, A. B. Shrivastav², A. K. Katiyar ${ }^{3}$, N. K. Jain ${ }^{3}$, V. S. Pillai ${ }^{4}$, Y. Verma ${ }^{3}$, \\ M. Swamy ${ }^{3}$ and G. Selvam ${ }^{5}$
}

\begin{abstract}
${ }^{1}$ Department of Veterinary Pathology, College of Veterinary Sciences and Animal Husbandry, Central Agricultural University Selesih, Aizawl - 796 014, Mizoram, India; ${ }^{2}$ Centre for Wildlife Forensics and Health, Nanaji Deshmukh Veterinary Science University, Jabalpur - 482 004, Madhya Pradesh, India; ${ }^{3}$ Department of Veterinary Pathology, College of Veterinary Science and Animal Husbandry, Nanaji Deshmukh Veterinary Science University, Jabalpur - 482 004, Madhya Pradesh, India; ${ }^{4}$ Veterinary Dispensary, Government of Kerala, Vallikunnam, Aleppey, Kerala, India; ${ }^{5}$ Department of Pathology, International Institute of Biotechnology and Toxicology (IIBAT), Padappai Kanchipuram - 601 301, Tamil Nadu, India
\end{abstract}

\begin{abstract}
In the presented study, the pathology of diclofenac sodium-induced visceral gout was investigated in domestic chicken, a validated experimental model for diclofenac toxicity for vultures. The experiment was conducted on eighteen day old commercial broiler chicks and 72 adult Leghorn chickens. The study was conducted in two phases to study the oral effects of diclofenac in young chicks and adult birds. Phase 1 of the trial was conducted for 15 days on young chicks. It comprised of three groups according to diclofenac dosing per $\mathrm{kg}$ body weight as $\mathrm{C}(0 \mathrm{mg} / \mathrm{kg}), \mathrm{C1}(0.25 \mathrm{mg} / \mathrm{kg}) \mathrm{and} \mathrm{C2}$ $(0.5 \mathrm{mg} / \mathrm{kg})$. Similarly, Phase 2 of trial on adult birds was conducted for 28 days, with three groups A (0 mg/kg), A1 (0.25 $\mathrm{mg} / \mathrm{kg})$ and $A 2(0.5 \mathrm{mg} / \mathrm{kg})$. In Phase 1 only two chicks died of diclofenac toxicity after showing clinical signs of extreme dullness and revealed visceral gout on necropsy. None of the other birds in both phases revealed mortality or gout till slaughter. The histopathology of dead chicks revealed tubular necrosis, while De Galantha's staining revealed the presence of urate deposits only in cortical tubules of kidneys. The medulla was not showing any urate deposits. Urate tophi were also seen in other parenchymatous organs. The slaughtered birds in either phase of the experiment revealed mild to moderate degenerative changes in the kidney and liver of diclofenac exposed birds. The findings indicate obstructive nephropathy as the cause of visceral gout in dead chicks.
\end{abstract}

Key words: Chicken, De-Galantha, Diclofenac, Urates, Visceral gout

\section{INTRODUCTION}

Vulture population in the Indian subcontinent declined due to indiscriminate use of veterinary grade diclofenac. Most affected species of vultures include (Gyps bengalensis, Gyps indicus and Gyps tenuirostris). Consequently, a phasing out order and ultimately a ban on total use of diclofenac in veterinary practice was introduced in the year 2006 (Prakash et al., 1999; Prakash et al., 2003; Oaks et al., 2004; Meteyer et al., 2005; Swan et al., 2006). The use of diclofenac continued in spite of the ban. It was reported that there was presence of diclofenac in liver and/or kidneys of vultures of various species (Gyps bengalensis, Gyps indicus and Gyps himalayensis) dying of visceral gout in India up to 2012. Other NSAID drugs found in dead vultures were meloxicam and nimesulide (Cuthbert et al., 2016). In a covert survey it was found that diclofenac was available for sale in India for veterinary practice up to the year 2017 (Galligan et al., 2020). The population of white rumped vulture in India improved a little and reached up to the level of 6000 . However it is still not at safer levels. In the subcontinent the vulture population recovery had been found to be better in Pakistan and Nepal as compared to

"Corresponding Author, E Mail: aryarahulsingh@gmail.com 
India (Chaudhry et al., 2012; Galligan et al., 2019; Prakash et al., 2019). Diclofenac is found to be affecting other vulture species and newer reports keep coming up. Recently HerreroVillar et al. (2021) reported the first case of diclofenac toxicity associated visceral gout in cinereous vulture (Aegypius monachus) a near threatened species of vultures from Europe.

Siller et al. (1981) classified visceral gout on etiopathology as 'retrograde or obstructive type' and 'nephrotoxic type'. In obstructive type gout there is an obstruction to urate flow. 'While in nephrotoxic type', there is a failure of reptilian type nephrons in bird's kidneys to secrete urates. It is widely accepted in principle, although overlapping of both may occur in some instances (Sturkie, 1986; Lumeij, 1994). The occurrence of hyperuricemia and visceral gout on exposure to diclofenac has been established beyond doubt in both vultures and domestic fowls (Oaks et al., 2004; Naidoo et al., 2007; Naidoo and Swan, 2009). The pathogenesis of visceral gout in diclofenac toxicity remains an enigma. All the histopathology reports in vultures (Oaks et al., 2004; Meteyer et al., 2005; Cunningham et al., 2006; Swan et al., 2006; Naidoo et al., 2009) and domestic fowl (Naidoo et al., 2007; Hussain et al., 2008) suffering from diclofenac toxicity show presence of urates tophi in kidney tubules and preferential necrosis of cortical tubules while glomeruli are spared.

It has also been found that vultures and chickens can survive exposure to diclofenac without developing visceral gout (Oaks et al., 2004; Naidoo et al., 2007; Hussain et al., 2008). The role of dehydration-induced obstructive nephropathy in the development of visceral gout in birds is well established (Siller et al., 1981; Sturkie, 1986; Lumeij, 1994). Whether dehydration has any role in the development of diclofenac-induced visceral gout in vultures and chicken has never been investigated. The use of diuretics and rehydration therapy to flush out affected kidneys is recommended in the management of visceral gout in birds (Sturkie, 1986). It has been reported with some success (frusemide and ringer's lactate) in Gyps vultures after showing signs of ketoprofen-induced renal toxicity (Naidoo et al., 2010) and diclofenac toxicity in chicken (Naidoo et al., 2007). Domestic fowl is a validated model to study diclofenac toxicity in vultures (Naidoo et al., 2007). After a long gap of about a decade, some new insight has emerged regarding the pathobiology of diclofenac sodium in birds taking chicken as a model of study. Recently it was reported that the diclofenac sodium can cause defects of midline closure in early chicken embryos (Ertekin et al., 2019). Sun et al. (2021) found evidence that the diclofenac sodium can cause apoptosis in chicken kidney cells and interferes with purine metabolism. Nethathe et al. (2021) found that diclofenac leads to alteration in renal perfusion and also renal plasma flow. This leads to death due to an extensive reduction in tubular secretion. Li et al. (2021) reported that in specific pathogen-free chicks diclofenac sodium can cause proliferation of harmful bacteria in intestines and reduce the number of beneficial bacteria.

The presented study was conducted to compare and investigate the pathology of repeated diclofenac exposure in domestic fowl of different age groups and sex.

\section{MATERIALS AND METHODS}

Statement of ethical treatment to experimental birds: An approval was obtained for the study from the Institutional Animal Ethics Committee (IAEC), College of Veterinary Science and Animal Husbandry, Jabalpur, Madhya Pradesh, India. There was no deviation from the guidelines of IAEC during the experiment.

Experimental birds: The experiment was conducted on eighteen day old commercial White Leghorn chicks procured from a local vendor and 72 adult Leghorn chickens with 36 males and 36 females, procured from the All India Coordinated Research Project on poultry in the College of Veterinary Science and 
Animal Husbandry, Jabalpur, Madhya Pradesh, India. The birds were housed under strict hygienic conditions and were fed standard poultry ration procured from the Department of Poultry Science of the institute. The birds were raised on the deep litter system and were provided feed and water ad libitum.

Experimental design: The study was conducted in two phases to study the effects of diclofenac in young chicks (Phase 1) and adult birds (Phase $2)$. The control and test birds were all kept in similar standard conditions of management. The respective dose of diclofenac was given orally in both phases at the dose rate of 0.25 $\mathrm{mg} / \mathrm{kg}$ and $0.5 \mathrm{mg} / \mathrm{kg}$ body weight (Table 1 and 2). In Phase 1, 15 days experimental trial was conducted with a maximum of six chicks in each group. Accordingly, a total of eighteen White Leghorn chicks of 1 day age were included in the trial to form three experimental groups as given in Table 1.

In Phase 2, 28 days experimental trial was conducted with a maximum of 24 birds (12 males and 12 females) in each group (Table 2). Accordingly, a total of 72 adult White Leghorn birds of either sex (36 male and 36 female) were included in the trial to form three experimental groups as given in Table 2. Young chicks were kept in a deep litter system, while adult birds were housed in cages. The birds were fed with standard ration and managed in the best of conditions. The dose rates for the experiment were decided according to earlier experiments conducted on domestic fowl (Naidoo et al., 2007; Hussain et al., 2008).

Necropsy and histopathology: The experimental birds were subjected to humane slaughter according to the guidelines of IAEC. A thorough scientific post mortem examination was conducted of the dead, and slaughtered birds and all the important gross observations were photographed and recorded. Representative tissue samples from the kidney, liver, spleen and heart of the birds were collected in $10 \%$ neutral buffered formalin (NBF) for routine hematoxylin and eosin (H\&E)

Table 1. Trial set up and mortality in Phase 1

\begin{tabular}{lcccccc}
\hline Groups & $\begin{array}{c}\text { No. of } \\
\text { birds }\end{array}$ & $\begin{array}{c}\text { Diclofenac } \\
\text { dose rate } \\
\text { (mg/kg body } \\
\text { weight) }\end{array}$ & $\begin{array}{c}\text { Day of } \\
\text { dosing }\end{array}$ & $\begin{array}{c}\text { Day of } \\
\text { slaughter* }\end{array}$ & Mortality & $\begin{array}{c}\text { Day of } \\
\text { mortality }\end{array}$ \\
\hline Control-C & 6 & 0 & $1 \& 7$ & 15 & Nil & NA \\
C 1 & 6 & 0.25 & $1 \& 7$ & 15 & 1 & 2 \\
C 2 & 6 & 0.50 & $1 \& 7$ & 15 & 1 & 2 \\
\hline
\end{tabular}

*All six chicks were slaughtered on day 15

Table 2. Trial set up in Phase 2

\begin{tabular}{lccccc}
\hline Groups & $\begin{array}{c}\text { No. of } \\
\text { birds }\end{array}$ & $\begin{array}{c}\text { Diclofenac } \\
\text { dose rate } \\
\text { (mg/kg body } \\
\text { weight) }\end{array}$ & $\begin{array}{c}\text { Day of } \\
\text { dosing }\end{array}$ & $\begin{array}{c}\text { Day of } \\
\text { slaughter* }\end{array}$ & Mortality \\
\hline Control-A & 24 & 0 & $1,8,15,22$ & $7,14,21,28$ & Nil \\
A1 & 24 & 0.25 & $1,8,15,22$ & $7,14,21,28$ & Nil \\
A2 & 24 & 0.50 & $1,8,15,22$ & $7,14,21,28$ & Nil \\
\hline
\end{tabular}

*Six birds ( 3 males and 3 females) were slaughtered on each day of slaughter 
Indian Journal of Animal Health, December, 2021

Diclofenac-induced visceral gout in domestic fowl

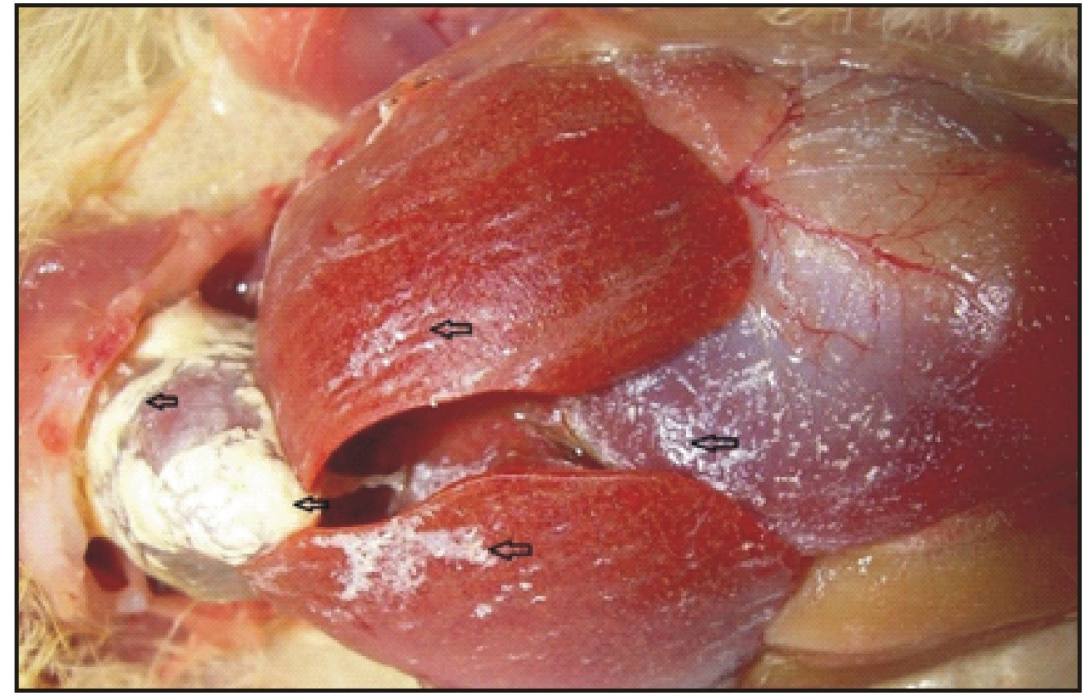

Fig. 1. Chalky white deposits on pericardium, surface of liver and other visceral organs (black arrow) seen in the chick dying of visceral gout
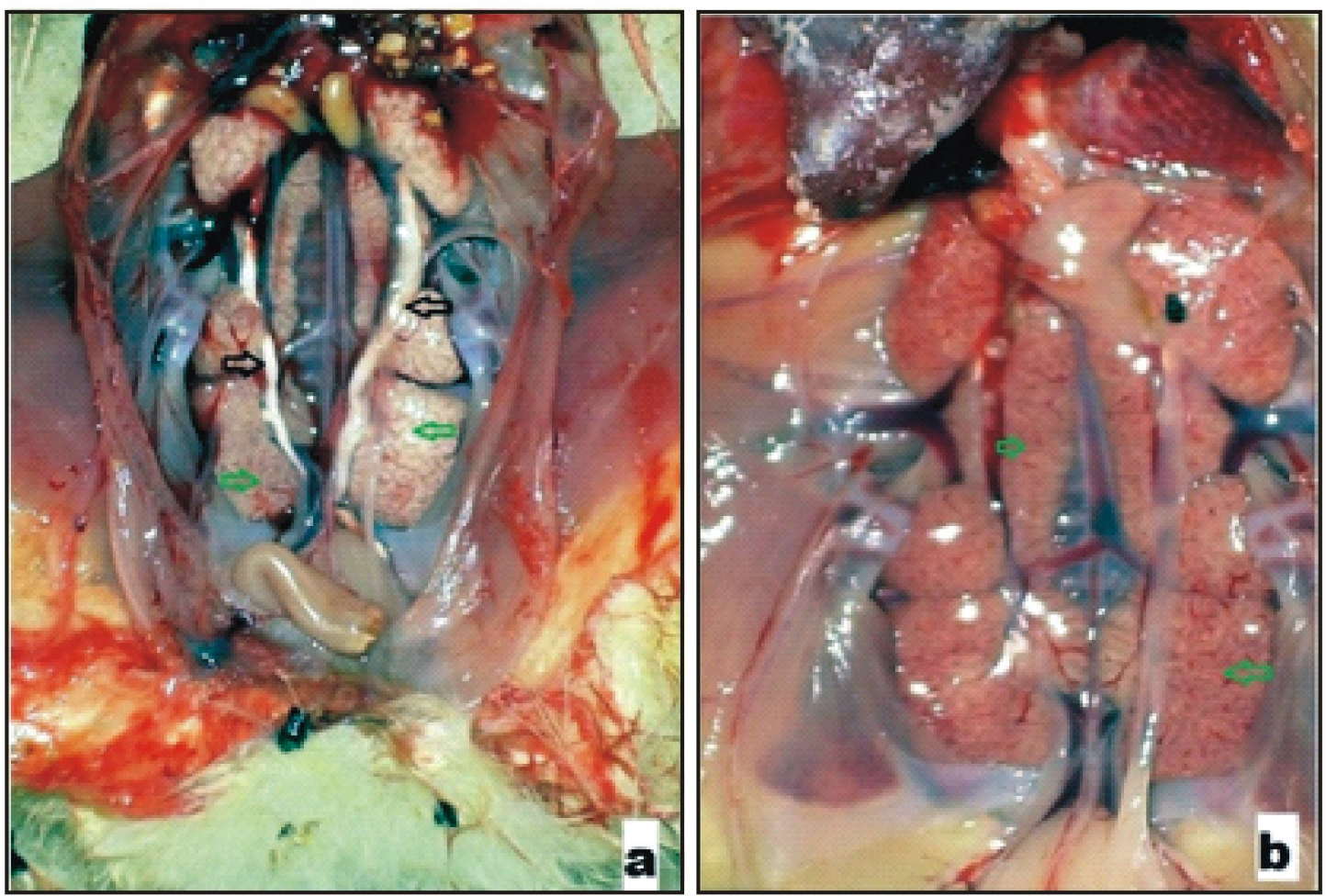

Fig. 2. a) Kidneys of dead chick from group $\mathrm{C} 1$ showing pale, swollen kidneys with whitish streaks in parenchyma (green arrow) and engorged ureters (black arrow), b) Kidneys of dead chick from group $\mathrm{C} 2$ showing pale, swollen kidneys with whitish streaks in parenchyma and congestion (green arrow) 
staining (Luna,1968). While, for demonstration of urates, the tissue samples from the kidney, liver, spleen and heart of dead chicks were collected in absolute alcohol and processed according to De-Galantha's method (DeGalantha, 1935; Luna, 1968). The procedure, in brief, is as follows: for staining the urates $5 \mathrm{~mm}$ thick tissue samples were dehydrated in absolute alcohol, cleared with xylene and were impregnated and embedded with paraffin wax. 7-8 $\mu \mathrm{m}$ thick micro-sections were obtained on glass slides. Sections were dewaxed in xylene and given two changes of absolute alcohol and were then exposed to strong sunlight in glass staining jars containing $10 \%$ silver nitrate until urates turned rose-red (approximately 3 hours). Freshly prepared developing solution (3\% gelatin- $10.0 \mathrm{~mL} ; 20 \%$ silver nitrate- $3.0 \mathrm{~mL}$; $2 \%$ Hydroquinone- $2.0 \mathrm{~mL}$ ) was poured over the slides until the urates turned black (2-4 seconds) and were then immediately washed with hot water $\left(58^{\circ} \mathrm{C}\right)$. Sections were then dehydrated directly in absolute alcohol, cleared in xylene and mounted with DPX mountant.

\section{RESULTS \\ Clinical signs}

Phase 1: After the $1^{\text {st }}$ dose, all the birds were normal in behavior for $4 \mathrm{hrs}$. By the end of 6 hours, feed and water intake of the chicks of both the test groups had reduced. It was evident by the remarkably increased amount of residual feed and water in the utensils as compared to the control group, which finished all the feed provided. The chicks were showing reduced alertness in both the test groups and one chick in each group was extremely dull, lethargic and sat away from other chicks with wings and head drooping. Both were off feed and did not try to escape when approached. They later died. Control chicks were alert as before and consumed maximum feed and water among all three groups. By $3^{\text {rd }}$ day of dosing the feed and water consumption resumed back to normal levels in both test groups. After $2^{\text {nd }}$ dose, again a reduction in activity, feed and water intake was observed; however, there was no mortality.
Phase 2: There were no remarkable signs in any of the test groups of adult birds after diclofenac sodium administration.

\section{Mortality}

Phase 1: One chick from each test group showing severe depression was found dead after about 22 hours post drug administration. The rest of the chicks resumed normal feed and water consumption by 24 hours post drug administration. There was no mortality after $2^{\text {nd }}$ dose.

Phase 2: No mortality was observed in any of the groups.

\section{Necropsy examination}

Phase 1: a. Dead chicks- On postmortem examination it was found that the carcass of both the chicks was dehydrated and had chalky white deposits over the surface of the liver, spleen, pericardium and other visceral organs (Fig. 1). Their kidneys were swollen, pale and revealed whitish streaks in the parenchyma indicating retention of urates (Fig. 2. a \& b).

b. Slaughtered chicks- None of the slaughtered chicks revealed any stage of visceral gout. However, some of them had congestion on the liver and kidneys.

Phase 2: None of the slaughtered adult birds revealed any stage of visceral gout. However, few of them had congested patches on the liver and kidneys.

\section{Histopathology and demonstration of urates Phase 1:}

a. Dead chicks

\section{i) Hematoxylin and Eosin staining}

Kidneys- In H\&E stained micro-sections, the kidney revealed tubules with necrotic, flattened epithelium and dilatation of lumen. Some tubules revealed the presence of basophilic content. There was mononuclear cell infiltration in the interstitial tissue. Glomeruli had dilated bowman's space and few vacuoles towards the periphery of the tuft (Fig. 3). 
Liver (H\&E) - The liver of dead chicks revealed sinusoidal dilatation and foamy cytoplasm of hepatocytes (Fig. 4) and also a few foci of coagulative necrosis.

\section{ii) De-Galantha's staining}

Kidneys - The micro sections of kidneys stained by De-Galantha's method revealed black urates against the yellow background of tissue. The majority of urate deposits were associated with renal tubules, and the cellular details around the deposits were not evident. The tubules laden with urates were seen only in the kidney cortex and some tubules in the medulla. There was no deposition in the glomeruli. The medullary tracts also had no deposits, and their lumina were empty (Fig. 5).

Liver - Liver revealed the presence of starshaped and needle-like deposits of urate crystals (Fig. 6).

Spleen - Spleen revealed the presence of star-shaped deposits of urate crystals.

Heart - Heart revealed the presence of starshaped deposits of urate crystals. The urate deposits were particularly dense around the epicardium.

\section{b. Slaughtered chicks}

In H\&E stained micro-sections of kidneys, there were no remarkable findings, and most foci revealed normal kidney parenchyma similar to the control group. However, in the chicks with congested kidneys, few isolated foci of nephrosis were observed. In H\&E stained micro-sections of the liver of the slaughtered chicks, most of the parenchyma was normal similar to the control group. However, in some chicks, few foci of mild to moderate vacuolar degeneration were observed. There were no remarkable changes in other visceral organs like the spleen, heart and lungs.

Phase 2: Slaughtered adult birds - There were no remarkable findings in the liver of the test birds as compared to the control group. However, in a few birds, in some foci, the hepatocytes revealed vacuolar degeneration and sinusoidal dilatation. There were no remarkable findings in the kidneys of the test birds as compared to the control group. However, in a few birds, in some foci of cortex coagulative necrosis and exfoliation in tubular epithelial cells was observed. There was no remarkable difference in pathological changes in the liver and kidneys of adult birds slaughtered at different intervals. There were no remarkable changes in other visceral organs.

\section{DISCUSSION}

Naidoo et al. (2007) found that the chicks that died of visceral gout after being injected with diclofenac were reluctant to move, perched in one corner of their cages, appeared to be asleep, had stopped eating and were severely depressed. This depression, on average, occurred at $24 \mathrm{~h}$ post-dosing and progressively became more severe. Before death, the affected birds appeared to be comatose. Hussain et al. (2008) found that in broiler chicken, the clinical signs appeared about 12 hours after diclofenac feeding and included depression, somnolence, sitting on hocks with closed eyes, reduced feed and water intake. It is to be noted that Cunningham et al. (2006) and Swan et al. (2006) reported similar signs in various species of Gyps vultures on diclofenac toxicity. The clinical signs observed in the test group chicks indicate a state of depression induced by the toxicity of diclofenac. The condition was more pronounced in those two chicks, which later developed gout and died. The clinical signs in these two chicks were very similar to those observed by other workers in domestic fowl (Naidoo et al., 2007; Hussain et al., 2008) and in vultures often called 'neck drooping' (Cunningham et al., 2006; Swan et al., 2006). The birds that developed gout did not feed or drink at all during the observation period, and consequently, their carcass was dehydrated. Dehydration has been considered as one of the etiological factors of gout (Lumeij, 1994) and had been considered a probable cause for gout in vultures (Cunningham et al., 2006). It has also been suggested that gavaging large 


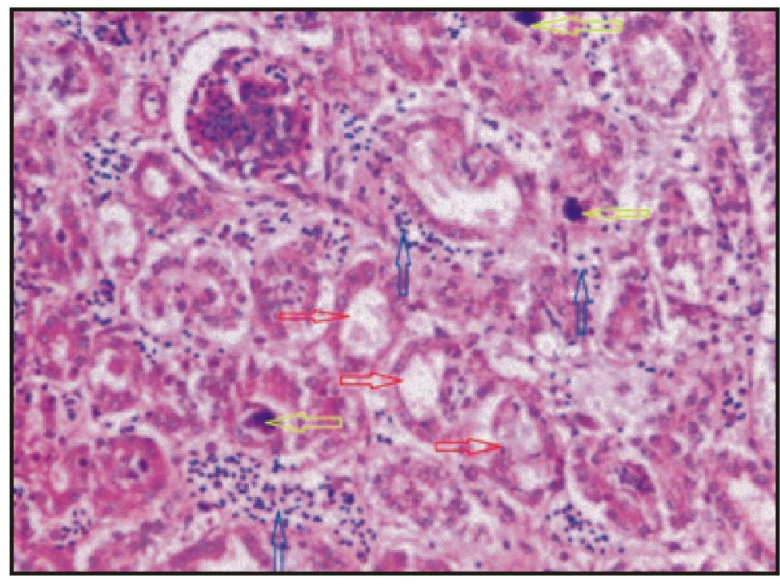

Fig. 3. Kidney, chicken (H\&E X 100): The cortical tubules show necrotic, flattened epithelium, dilatation of lumen (red arrow), presence of basophilic content in some tubules (yellow arrow) and mononuclear cell infiltration in interstitial tissue (blue arrow). Glomerulus shows dilated bowman's space and few vacuoles towards the periphery of the tuft

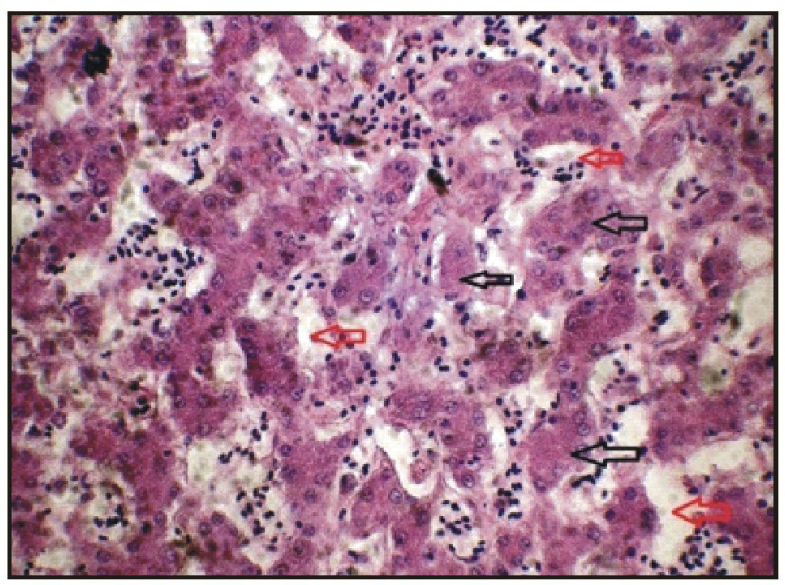

Fig. 4. Liver, chicken (H\&E X 600): The liver of dead chick (CI group) showing dilated sinusoids (red arrow). The hepatocytes are showing foamy cytoplasm (black arrow)

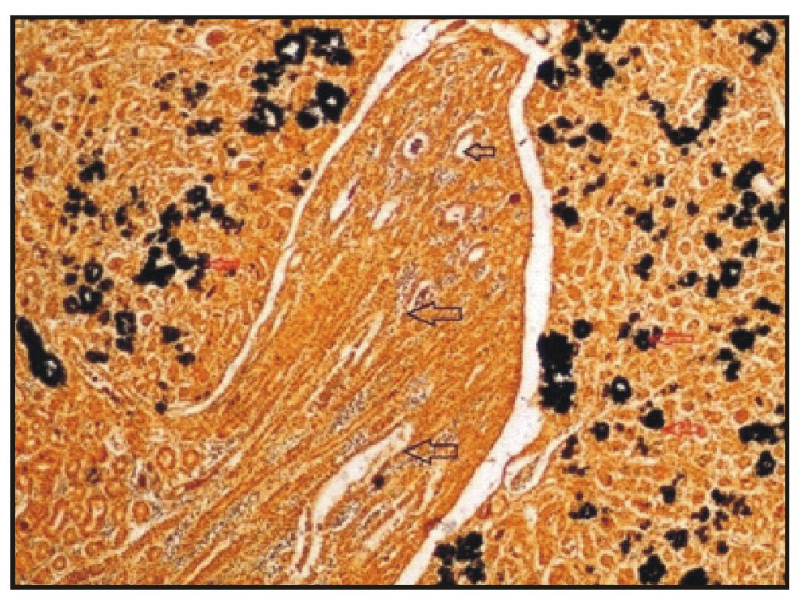

Fig. 5. Kidney, chicken (De-Galantha's staining $X$ 40): The cortical tubules show presence of black urate deposits (red arrow) while the medullary tract is free of any urates (black arrow)

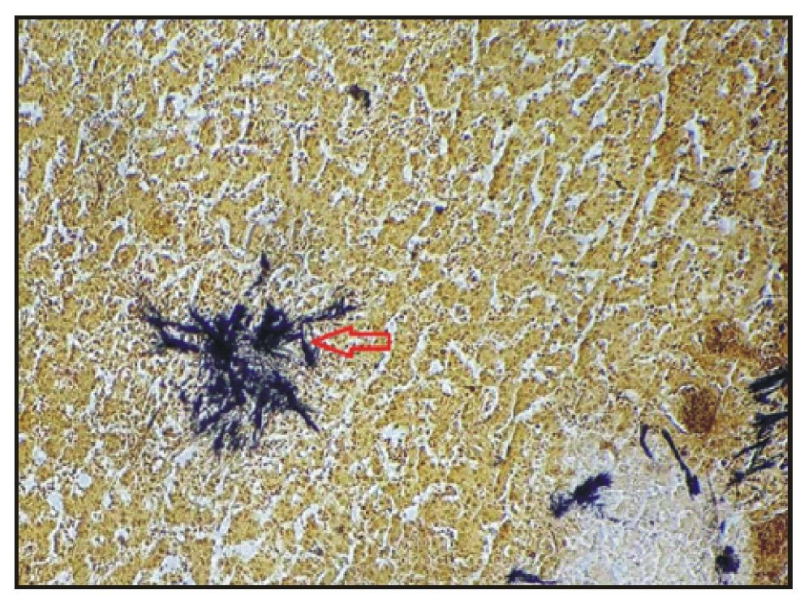

Fig. 6. Liver, chicken (De-Galantha's staining $X$ 100): The liver shows presence of urate tophi as radiating deposits of black needle shaped crystals (red arrow) 
quantities of water to flush out the affected kidneys can help manage diclofenac-induced gout in domestic fowl (Naidoo et al., 2007). Moreover, there is a report that administration of ringer's lactate and furosemide could save a Gyps vulture from ketoprofen toxicosis even after the development of clinical symptoms. Here it should be noted that pathological changes caused by ketoprofen in vulture kidneys were similar to those caused by diclofenac (Naidoo et al., 2009).

Mortality in chicken on exposure to diclofenac had been reported earlier (Naidoo et al., 2007; Hussain et al., 2008). In the presented study, mortality was observed only in chicks at 2 days of age, which indicates the age resistance to diclofenac sodium in chicken. Hussain et al. (2008) reported the mortality in diclofenac fed broiler chicks at much higher doses of $2.5,10$ and $20 \mathrm{mg} / \mathrm{kg}$. While at dose levels of $0.25 \mathrm{mg} / \mathrm{kg}$ as in our experiment they found no mortality throughout the experiment. Except for the $20 \mathrm{mg} / \mathrm{kg}$ dose rate, all other groups had surviving birds like in our experiment, where there was no mortality after the first episode. Another similarity was that the first episode of mortality in their experiment occurred on the $2^{\text {nd }}$ day, which is the same as in our study. There are reports that diclofenac exposed vultures can survive and may not develop visceral gout (Oaks et al., 2004; Muralidharan and Dhananjayan, 2010). The findings of the present study are in agreement with other studies conducted on domestic chicken and vultures.

All the histopathology reports in vultures (Oaks et al., 2004; Meteyer et al., 2005; Cunningham et al., 2006; Swan et al., 2006; Naidoo et al., 2009) and domestic fowl (Naidoo et al., 2007; Hussain et al., 2008) suffering from diclofenac toxicity show presence of urates tophi in kidney tubules and preferential necrosis of cortical tubules while glomeruli are spared. Routine histopathology by H\&E staining is not equipped to reveal the pattern of urate deposition in the affected organs, especially kidneys. Therefore, techniques like
De Galantha's staining are essential because they conserve the urate depositions during fixation and also processing (De-Galantha, 1935; Luna, 1968). De-Galantha's method for the histochemical demonstration of urates was employed for the first time to study the diclofenac toxicity. The pattern of urate deposition in kidneys can indicate whether it is obstructive nephropathy or toxic necrosis of renal tubules in birds dying of diclofenac induced visceral gout. If it is purely toxic gout, then the tubules are generally empty. Or, if it is obstructive type, then the tubules should show engorgement of urates. None of the studies on diclofenac toxicity in vultures or domestic fowl employed De-Galantha's technique to study the pattern of urate deposition in kidneys of affected birds.

The urate engorgement was observed only in the cortical tubules. Glomeruli and lumina of kidney medullary tubules were free of the presence of urates. This confirms the obstructive nephropathy in the chicks dying of visceral gout. In $\mathrm{H} \& \mathrm{E}$ staining, cortical tubules appear dilated with atrophied necrotic epithelium and also show amorphous basophilic content in some tubules, which all prove engorgement of cortical tubules with urates. The observed changes confirm obstructive nephropathy in chicks dying of visceral gout according to etiopathology of visceral gout given by Siller et al. (1981). The pathological changes in slaughtered chicks and adult birds were mild to moderate, and similar to earlier reports (Naidoo et al., 2007; Hussain et al., 2008). Moreover, they also did not reveal any remarkable difference in the pathological changes at different slaughters in each phase. This indicates that at given doses, diclofenac can cause only mild to moderate degenerative changes in the liver and kidneys of exposed chicks and adult birds. Also, there was no remarkable sex-based difference in pathological changes observed in adult birds. The pathological changes in the kidneys of slaughtered birds were not sufficient enough to cause kidney failure and visceral gout even 
on prolonged exposure.

It was concluded that the diclofenac toxicity in young chicks could lead to visceral gout. Adult birds are relatively tolerant to diclofenac toxicity as compared to young chicks. Young chicks also revealed increased tolerance to diclofenac with an increase in age. Apart from visceral gout, diclofenac can also cause mild to moderate degenerative changes in the kidneys and the liver at the given dose rates with no remarkable difference according to age or sex. The De-Galantha's staining confirmed obstructive nephropathy in chicks dying of

\section{REFERENCES}

Chaudhry JMI, Ogada DL, Malik RN, Virani MZ and Giovanni MD, 2012. First evidence that populations of the critically endangered Longbilled Vulture Gyps indicus in Pakistan have increased following the ban of the toxic veterinary drug diclofenac in South Asia. Bird Conserv Int, 22: 389-397, doi: 10.1017/S0959270912000445

Cunningham AA, Prakash V, Pain D, Ghalsasi GR, Wells GAH et al., 2006. Indian vultures: victims of an infectious disease epidemic? Anim Conserv, 6(3): 189-197, doi: 10.1111/j.16000447.1973.tb10467.x

Cuthbert RJ, Taggart MA, Saini M, Sharma A, Das A et al., 2016. Continuing mortality of vultures in India associated with illegal veterinary use of diclofenac and a potential threat from nimesulide. Oryx, 50(01): 104-112, doi: 10.1017/ S003060531500037X

De-Galantha E, 1935. Silver stain for urates. Am J Clin Pathol, 5: 165-166

Ertekin T, Bilir A, Aslan E, Koca B, Turamanlar O et al., 2019. The effect of diclofenac sodium on neural tube development in the early stage of chick embryos. Folia Morphol, 78(2): 307-313, doi: 10.5603/FM.a2018.0080

Herrero-Villar M, Delepoulle É, Suárez-Regalado L, Solano-Manrique C, Juan-Sallés C et al., 2021. First diclofenac intoxication in a wild avian scavenger in Europe. Sci Total Environ, 782: 146890, doi: 10.1016/j.scitotenv.2021.146890

Hussain I, Khan MZ, Khan A, Javed I and Saleemi MK, 2008. Toxicological effects of diclofenac in four avian species. Avian Pathol, 37(3): 315-321, doi: $10.1080 / 03079450802056439$

Galligan TH, Bhusal KP, Paudel K, Chapagain D, Joshi visceral gout.

Conflict of interest: Authors have no conflict of interest in this study.

\section{ACKNOWLEDGEMENTS}

The authors are thankful to the Dean CVSc \& AH, NDVSU, Jabalpur; the Head, Department of Animal Nutrition, CVSc \& AH, NDVSU, Jabalpur, and the authority, Phoenix Poultries limited Jabalpur for providing necessary facilities for conducting the presented study.

AB et al., 2019. Partial recovery of critically endangered Gyps vulture populations in Nepal. Bird Conserv Int, 30(1): 87-102, doi: 10.1017/ S0959270919000169

Galligan TH, Mallord JW, Prakash VM, Bhusal KP, Alam AS et al., 2020. Trends in the availability of the vulture-toxic drug, diclofenac, and other NSAIDs in South Asia, as revealed by covert pharmacy surveys. Bird Conserv Int, 31(3): 337353, doi: 10.1017/S0959270920000477

Li Z, Lin S, Sun C, Huang Z, Liu H et al., 2021. Toxicological effects of diclofenac sodium in duodenum tissue and intestinal microorganisms of chickens. Worlds Poult Sci J, 11(2): 259-270, doi: 10.36380/jwpr.2021.31

Lumeij JT, 1994. Nephrology. In: Ritchie BW, Harrison GJ, Harrison LR, editors. Avian medicine. Principles and application. Lake Worth, Wingers Publishing, pp 538-555

Luna LG, 1968. Manual of histologic staining methods of the armed forces institute of pathology. 3rd edn., New York, Blakiston Division McGraw-Hill, pp 1-46

Meteyer CU, Rideout BA, Gilbert M, Shivaprasad HL and Oaks JL, 2005. Pathology and proposed pathophysiology of diclofenac poisoning in freeliving and experimentally exposed oriental whitebacked vultures (Gyps bengalensis). J Wildlif Dis, 41(4): 707-716, doi: 10.7589/0090-3558-41.4.707

Muralidharan S and Dhananjayan V, 2010. Diclofenac residues in blood plasma and tissues of vultures collected from Ahmedabad, India. Bull Environ Contam Toxicol, 85(4): 377-380, doi: 10.1007/ s00128-010-0109-7

Naidoo V, Duncan N, Bekker L and Swan G, 2007. Validating the domestic fowl as a model to 
investigate the pathophysiology of diclofenac in Gyps vultures. Environ Toxicol Pharmacol, 24(3): 260266, doi: 10.1016/j.etap.2007.06.003

Naidoo V and Swan GE, 2009. Diclofenac toxicity in Gyps vulture is associated with decreased uric acid excretion and not renal portal vasoconstriction. Comp Biochem Physiol C Toxicol Pharmacol, 149(3): 269-274, doi: 10.1016/j.cbpc.2008 .07 .014

Naidoo V, Wolter K, Cuthbert R and Duncan N, 2009. Veterinary diclofenac threatens Africa's endangered vulture species. Regul Toxicol Pharmacol, 53(3): 205-208, doi: 10.1016/ j.yrtph.2009.01.010

Naidoo V, Wolter K, Cromarty D, Diekmann M, Duncan $\mathrm{N}$ et al., 2010. Toxicity of non-steroidal anti-inflammatory drugs to Gyps vultures: A new threat from ketoprofen. Biol Lett. 6(3): 339-341, doi: 10.1098/rsbl.2009.0818

Nethathe B, Chipangura J, Hassan IZ, Duncan N, Adawaren EO et al., 2021. Diclofenac toxicity in susceptible bird species results from a combination of reduced glomerular filtration and plasma flow with subsequent renal tubular necrosis. Peer J, 9: e12002, doi: 10.7717/peerj.12002

Oaks JL, Gilbert M, Virani MZ, Watson RT, Meteyer CU et al., 2004. Diclofenac residues as the cause of population decline of vultures in Pakistan. Nature, 427: 630-633, doi: 10.1038/nature02317 Prakash V, Pain DJ, Cunningham AA, Donald PF,
Prakash N et al., 2003. Catastrophic collapse of Indian white-backed Gyps bengalensis and longbilled Gyps indicus vulture populations. Biol Conserv, 109(3): 381-390, doi: 10.1016/S00063207(02)00164-7

Prakash V, 1999. Status of vultures in Keoladeo National Park, Bharatpur, Rajasthan, with special reference to population crash in Gyps species. J Bombay Nat Hist Soc, 96: 365-378

Prakash V, Galligan TH, Chakraborty SS, Dave R, Kulkarni MD et al., 2019. Recent changes in populations of critically endangered Gyps vultures in India. Bird Conserv Int, 29(1): 55-70, doi: $10.1017 /$ S0959270917000545

Siller WG, 1981. Renal pathology of the fowl - A review. Avian Pathol, 10(3): 186-262, doi: 10.1080/03079458108418474

Sturkie PD, 1986. Kidneys, extrarenal salt excretion, and urine. Springer-Verlag New York, Inc, pp 359-382, doi: 10.1007/978-1-4612-4862-0_16

Sun C, Lin S, Li Z, Liu H, Liu Y et al., 2021. iTRAQbased quantitative proteomic analysis reveals the toxic mechanism of diclofenac sodium on the kidney of broiler chicken. Comp Biochem Physio C Toxicol Pharmacol, 249: 109129, doi: 10.1016/ j.cbpc. 2021.109129

Swan GE, Cuthbert R, Quevedo M, Green RE, Pain DJ et al., 2006. Toxicity of diclofenac to Gyps vultures. Biol Lett, 2(2): 279-282, doi: 10.1098/ rsbl.2005.0425

Received - 03.08.21, Accepted - 16.11.2021, Published - 01.12.2021

Section Editor: Prof. S. N. Joardar, Associate Editor 